\title{
PROGRAMA DE PÓS-GRADUAÇÃO DA ESCOLA DE ENFERMAGEM DE RIBERÃO PRETO DA UNIVERSIDADE DE SÃO PAULO
}

Tokico Murakawa Moriya*

A Escola de Enfermagem de Ribeirão Preto da Universidade de São Paulo, mantém três Programas de Pós-Graduação: Área Enfermagem Funcional a nível de Mestrado e de Doutorado; Área de Enfermagem Psiquiátrica a nível de Mestrado; Área Enfermagem em Saúde Pública a nível de Mestrado.

Além destes programas esta Escola mantém um programa Interunidades a nível de Doutorado juntamente com a Escola de Enfermagem de São Paulo, situada na Capital do Estado.

São as seguintes linhas de pesquisa dos programas:

\section{Áreas Enfermagem Psiquiátrica}

1) Enfermagem em Saúde Mental e Psiquiátrica

Descrição: Estudo relativo as várias fases do desenvolvimento humano e a assistência de Enfermagem junto à população geral e a grupos de riscos, em particular, nos diferentes níveis de prevenção. Estudos epidemiológicos. Enfermagem de Saúde Mental e Psiquiátrica em Instituições Assistenciais.

02) Recursos Humanos em Enfermagem

Descrição: Análise Crítica do Recursos Humanos em Enfermagem, referente a aspectos de sua formação (formal e informal) e atuação, bem como às relações com as equipes de enfermagem e demais profissionais da Área da Saúde. Ações educativas e administrativas do enfermeiro.

03) Psicopedagogia em Enfermagem

Descrição: Psicologia do adulto e a andragogia em enfermagem. Variáveis relevantes no relacionamento de saúde de profissionais, clientes, alunos, docentes e enfermeiros.Saúde mental e suas relações com maturidade e desenvolvimento. Enfermagem Psiquiátrica.

04)Estudos Teóricos, Históricos e da Prática de Enfermagem

Descrição: Estudos epistemológicos e bioéticos em Enfermagem, marcos referenciais, teorias e modelos de enfermagem. Pesquisas de perspectiva filosófica, histórica, sociológica e bioética. Análise crítica do saber e da prática na enfermagem.

\section{Área Enfermagem Fundamental}

1) Assistência de Enfermagem

Descrição: Avaliação de técnicas e procedimentos, auto-cuidado à saúde. Testagem das teorias e conceitos de Enfermagem. Estudo de modelos de assistência.

2) Análise Crítica da Profissão

Descrição: Análise dos aspectos históricos, sociais, filosóficos da profissão e estudo metodológico da pesquisa em enfermagem.

3) Infecção Hospitalar e seu Controle

Descrição: Estudo da epidemiologia de incidência de microorganismos. De fatores de

*Presidente da Comissão de Pós-Graduação e Professora Doutora da Escola de enfermagem de Ribeirão Preto da Universidade de São Paulo. 
risco e de metodologia de controle de infecção hospitalar.

4) Enfermagem nos Programas de Nutrição e Alimentação

Descrição: Atuação do enfermeiro nos programas de nutrição e alimentação.

5) Enfermagem Comunitária

Descrição: Estudo de atitudes e comportamentos de população frente à saúde.

6) Comunicação em enfermagem

Descrição: estudo do processo de comunicação nas diferentes bases do Sistema de Saúde.

\section{Área Enfermagem em Saúde Publica}

1) Saúde da Mulher

Descrição: Objetiva investigar as atividades de assistência integral clínica, obstétrica, ginecológica e educativa, voltadas para o aprimoramento da mulher, como também estudar os problemas bio-sócio-psico-existenciais causados pelos múltiplos papéis sociais da mulher.

2) Saúde da Criança

Descrição: A saúde da criança é aprendida através de diferentes fundamentações teóricas e metodológicas. Visa a análise da assistência de enfermagem à criança, em diferentes fases do crescimento e desenvolvimento em sua dimensão coletiva e a prática da hospitalização de crianças.

3) Saúde Pública

Descrição: Objetiva o estudo das questões da assistência, do ensino e da pesquisa na área se saúde pública tendo em vista buscar conhecimento para o exercício das funções ampliadas do enfermeiro, a obtenção de tecnologia apropriada, a proposição de alternativas metodológicas para o ensino e a atuação em atenção à saúde.

4) Enfermagem como Prática Social

Descrição: Objetiva analisar o processo de trabalho em enfermagem articulado ao trabalho na saúde, caracterizando os meios de trabalho, seus agentes, objetos, e finalidades, na sua dimensão histórica e social.

O Programa Interunidades de Doutorados em Enfermagem, em Ribeirão Preto, engloba as mesmas linhas de pesquisa dos programas das áreas anteriormente citadas.

A seleção dos alunos para os programas é anual, com inscrição no mês de outubro.

São os seguintes os requisitos para as mesmas:

Área Enfermagem Fundamental: poderão se inscrever os candidatos com título de enfermeiro. Solicita-se contato prévio com o orientador;

Área Enfermagem Psiquiátrica: poderão se inscrever os candidatos com o título de enfermeiro, com experiência comprovada de no mínimo 01 ano em Saúde Mental ou Curso de Especialização na Área;

Área Enfermagem em Saúde Pública: poderão se inscrever os candidatos com o título de enfermeiro, e outros profissionais da área de Saúde, que tenham no mínimo 01 ano de experiência profissional no ensino e no serviço na área de saúde.

O número de vagas dos cursos é fixado anualmente ouvidas as disponibilidades dos programas.

Os critérios para a seleção das candidatos a estes programas são definidos pelas respectivas áreas. 